\title{
Mathematical modelling of the oxyfuel gasification of pulverized coal fuel
}

\author{
Igor Donskoy ${ }^{1, *}$ \\ ${ }^{1}$ Melentiev Energy Systems Institute, SB RAS, 130 Lermontova st,, Irkutsk, Russia
}

\begin{abstract}
In this work, we studied the efficiency of the coal gasification process under oxyfuel conditions. Using mathematical modelling one-dimensional stationary statement, the optimal parameters of coal processing were determined, air and oxyfuel conditions are compared. The calculated dependences of the characteristics of the gasification process on the stoichiometric ratio at different initial temperatures are constructed. The optimal values of oxygen stoichiometric ratio and the maximum values of cold gas efficiency in the selected range of parameters are determined. The contribution of the thermophysical and reactive properties of the gasification agent to the change in the cold gas efficiency is estimated.
\end{abstract}

\section{Introduction}

The proposed methods for suppression of carbon dioxide emissions from fossil fuels combustion can be divided into preventive ones, such as increasing the technical efficiency of thermal power plants, reducing the share of combustion by increasing the power of renewable and nuclear energy [1]; and utilizing ones, including $\mathrm{CO}_{2}$ binding/disposal in compressed/liquefied/mineral form (carbon capture and storage, CCS [2, 3]) and its absorption by biomass (for example, in the form of energy plantations) [4]. Prospects for reducing the costs of $\mathrm{CO}_{2}$ disposal are opened using new coal technologies, such as integrated gasification combined cycle (IGCC) and combustion in oxygen-enriched atmosphere (oxyfuel) [5, 6]. In this case, the usual combined cycle is realized using gasification products, and $\mathrm{CO}_{2}$ is extracted in two possible ways. The first is the removal of carbon at the pre-combustion stage, when the generator gas is converted by steam, which allows the use of $\mathrm{CO}$ to obtain additional $\mathrm{H}_{2}$, then the conversion products are separated by absorption or membrane methods, after which the hydrogen-enriched gas is burned in gas turbine, and $\mathrm{CO}_{2}$ is concentrated and sent for burial. The second method is the removal of carbon from the combustion products, similar to that for traditional CCS systems: the gas mixture is cooled to condensation conditions, after which the $\mathrm{CO}_{2}$ is separated from other gases and buried. The oxyfuel combustion technology is called to simplify the $\mathrm{CO}_{2}$ emission in the postcombustion variant, when the oxygen concentration in the blast is usually higher than in air, and the mixture of combustion products $\left(\mathrm{CO}_{2}\right.$ and $\left.\mathrm{H}_{2} \mathrm{O}\right)$ plays the role of diluent instead of nitrogen. Combustion in oxyfuel-mode has better environmental characteristics compared to traditional combustion in air: firstly, it is obvious that less nitrogen oxides are formed (mainly fuel oxides); secondly, the produced flue gases can be purified to high concentrations of $\mathrm{CO}_{2}$, allowing its simple utilization (disposal). By adjusting the $\mathrm{CO}_{2}$ supply, the intensity of combustion and heat transfer in combustion/gasification chamber can be controlled [7]. The oxyfuel technology is considered the most technically efficient, but at the same time one of the most expensive CCS systems [8, 9]. Among other problems, the requirements for the purification of flue gases from sulfur and nitrogen oxides can be noted [5]. Combined oxyfuel-combustion technologies are studied, for example, oxyfuel-MILD (decrease in oxygen concentration and increase in blast temperature) [10], the use of $\mathrm{CO}_{2}$ as a blast or transport agent in pulverized coal gasification [11-13].

Recirculation of combustion products allows controlling the thermal regimes of fuel conversion: for example, in [14] a decrease in the combustion temperature in a fluidized bed by $100 \mathrm{~K}$ under oxyfuel conditions is reported; paper [15] describes a pilot plant with staged gasification of coal, where it was possible to increase the degree of carbon conversion (up to 90-95\%) by adding $\mathrm{CO}_{2}$ to the input air. Calculations in work [13] show that an increase in $\mathrm{CO}_{2}$ concentration can lead to instability of the coal jet flame: under gasification conditions, it is necessary to increase the specific consumption of the oxidizing agent or the oxygen concentration to maintain the stability of the process. One way to increase the stability of the flame may be to heat the blast to the ignition temperature of fuel particles [16-18]. Earlier estimates of high-temperature air-steam coal gasification process efficiency $[19,20]$ and energy production at coal-fired IGCC using this technology [17, $21,22]$ showed that, when choosing suitable conditions, heating the blast allows maintaining high energy efficiency without oxygen enrichment. However, an increase in efficiency due to external heat is only possible with the supply of a suitable gasification agent

\footnotetext{
* Corresponding author: donskoy.chem @mail.ru
} 
(for example, with significant additions of steam). In this paper, using mathematical modeling, we study the efficiency of the pulverized coal gasification process using high-temperature blasting along with $\mathrm{CO}_{2}$ recirculation.

\section{Mathematical model}

In this work, computational tool is used that allows finding values for fuel consumption in different operating modes of the gasifier (described in detail in $[23,24])$. By simplifying the model, such calculations can be carried out in a wide range of conditions for the relatively short computational time. The calculation of the process as a whole is carried out as follows. The algorithm is based on the repeated use of a numerical model of the reacting fuel particle in changing thermal field:

$$
U c_{p} \frac{d\left(m_{p} T_{p}\right)}{d z}=\alpha S_{p}\left(T_{g}-T_{p}\right)+\varepsilon \sigma S_{p}\left(T_{w}^{4}-T_{p}^{4}\right)+\sum_{j} Q_{j} r_{j}
$$

In eq. (1) $z$ is spatial coordinate (reaction zone length), $\mathrm{m} ; U$ is particle velocity, $\mathrm{m} / \mathrm{s} ; m_{p}$ is particle mass, $\mathrm{kg} ; T_{p}$ is particle temperature, $\mathrm{K} ; c_{p}$ is particle heat capacity, $\mathrm{J} / \mathrm{kg} / \mathrm{K} ; \alpha$ is heat transfer coefficient, $\mathrm{W} / \mathrm{m}^{2} / \mathrm{K}$; $S_{p}$ is internal surface area of particle, $\mathrm{m}^{2} ; \varepsilon$ is particle surface emissivity; $\sigma$ is Stefan-Boltzmann constant, $\mathrm{W} / \mathrm{m}^{2} / \mathrm{K}^{4} ; \quad T_{g}$ is gas temperature, $\mathrm{K} ; T_{w}$ is wall temperature, $\mathrm{K} ; r_{j}$ is rate of physicochemical process (drying, pyrolysis, gasification reaction), $\mathrm{kg} / \mathrm{s} ; Q_{j}$ is heat of a reaction, $\mathrm{J} / \mathrm{kg}$.

Equation for drying rate $r_{d r}$ depends on temperature:

$$
r_{d r}=\left\{\begin{array}{l}
\frac{\beta S_{p} M_{H_{2} \mathrm{O}}}{R_{g} T}\left(P_{\mathrm{H}_{2} \mathrm{O}}^{e q}-P_{\mathrm{H}_{2} \mathrm{O}}\right), T_{p} \leq T_{b} \\
\frac{\alpha S_{p}\left(T_{g}-T_{p}\right)+\varepsilon \sigma S_{p}\left(T_{w}^{4}-T_{p}^{4}\right)}{\left|Q_{d r}\right|}, T_{p}>T_{b}
\end{array}\right.
$$

Here $T_{b}$ is boiling temperature under given pressure, $\mathrm{K} ; \beta$ is mass transfer coefficient, $\mathrm{m} / \mathrm{s} ; P_{H 2 O}-$ partial pressure of water vapours, $\mathrm{Pa} ; R_{g}-$ universal gas constant, $\mathrm{J} / \mathrm{mol} / \mathrm{K}$.

Pyrolysis rate $r_{p y r}$ depends on temperature as follows:

$$
r_{p y r}=k_{p y r} \exp \left(-\frac{E_{p y r}}{R_{g} T_{p}}\right) m_{V}
$$

Here $k_{p y r}$ is preexponential factor, $1 / \mathrm{s} ; E_{p y r}$ is apparent activation energy, $\mathrm{J} / \mathrm{mol} ; m_{V}$ is volatile fraction of particle, $\mathrm{kg}$.

Heterogeneous reactions proceed according to diffusional kinetics equation [25]:

$$
r_{g}=\frac{\frac{S_{p} C_{g}}{k_{g} e^{-\frac{E_{g}}{R_{g} T}}+\frac{d_{p}}{N u_{D} D_{g}}}}{\text {. }}
$$

Here $C_{g}$ is gasification agent concentration $\left(\mathrm{O}_{2}, \mathrm{CO}_{2}\right.$, $\left.\mathrm{H}_{2} \mathrm{O}\right), k_{g}$ is preexponential factor of heterogeneous reaction, $\mathrm{m} / \mathrm{s} ; E_{g}$ is activation energy, $\mathrm{J} / \mathrm{mol} ; N u_{D}$ is mass transfer Nusselt number; $D_{g}$ is diffusivity of gaseous oxidizer, $\mathrm{m}^{2} / \mathrm{s} ; d_{p}$ is averaged particle size, $\mathrm{m}$. Heat of a reaction $Q_{j}$ is estimated based on thermochemistry date base [26]. Diffusivities $D_{g}$ are calculated based on data [27]: diffusivities $\mathrm{O}_{2}$ and $\mathrm{H}_{2} \mathrm{O}$ are binary diffusivities in mixtures with $\mathrm{CO}_{2}$ or $\mathrm{N}_{2}$ as diluent; diffusivity of $\mathrm{CO}_{2}$ in oxyfuel conditions is self-diffusion coefficient. Particle velocity is considered as equal to gas velocity that is determined by continuity equation. Gas composition in every section is considered to be at chemical equilibrium under fixed fuel conversion degree [23, 28]. Numerical solution of a whole equation system is obtained as follows: the kinetics of chemical transformations is calculated using a system of ordinary differential equations (2-4) to change the particle mass for a given temperature distribution; then the stationary problem of heat transfer (1) is solved taking into account heat sources.

Chemical kinetics of reactions in the gas phase is not considered: it is assumed that the substances entering the gas phase quickly reach equilibrium. Thus, chemical transformations are described using a thermodynamic model with macrokinetic constraints on the fuel conversion degree. This approach is applicable for hightemperature processes in which the rate of gas-phase processes is quite high compared to the rate of heterophase ones. In this case, the task of calculating the gas composition is as follows [29]:

Find $\min G\left(\mathbf{n}^{g}\right)$

under constraints:

$$
\begin{aligned}
G\left(\mathbf{n}^{g}\right)= & \sum_{j} n_{j}^{g}\left(\mu_{j}^{0}+R_{g} T_{g} \ln \frac{P n_{j}^{g}}{\sum_{k} n_{k}^{g}}\right) \\
& \mathbf{A n}^{g}=\mathbf{b} \\
& \mathbf{n}^{g} \geq 0
\end{aligned}
$$

Here $G$ is Gibbs free energy, $\mathrm{J} ; \mathbf{n}^{g}$ is gas phase composition, mol; $\mu^{0}-$ is a chemical potential, $\mathrm{J} / \mathrm{mol}$; $P$ is pressure, atm; $\mathbf{A}$ is matrix of atomic composition; $\mathbf{b}$ is vector containing amounts of atoms, mol. In this case, Gibbs free energy is chosen in order to simplify the calculations: in a stationary state, the local temperature can be considered a constant parameter. The temperature values are iteratively refined when solving equations (1) and (2-4).

The amount of carbon entering the gas phase during gasification is taken into account as an amendment to vector $\mathbf{b}$, which, in addition to the elemental composition of the initial gas phase, includes a change in the elemental composition of solid fuel during pyrolysis and gasification.

\section{Results and discussion}

Entrained flow gasifier is considered with internal diameter of $3 \mathrm{~m}$ and length of $15 \mathrm{~m}$. Fuel is pulverized coal with following characteristics: $W^{r}=2 \% ; A^{d}=$ $15.38 \% ; V^{\text {daf }}=29.42 \% ; C^{\text {daf }}=85.45 \% ; H^{\text {daf }}=4.86 \%$; $N^{d a f}=2 \% ; S^{d a f}=0.67 \%$; averaged particle size os 100 $\mu \mathrm{m}$. Mixtures of $\mathrm{O}_{2} / \mathrm{N}_{2}$ and $\mathrm{O}_{2} / \mathrm{CO}_{2}$ are used as gasification agent. An example of calculations based on the model described above is presented at Figs. 1 and 2 
for following conditions: initial gasification agent temperature is $573 \mathrm{~K}$, operating pressure is $30 \mathrm{~atm}$, oxygen concentration is $20 \%$ vol., fuel consumption is $100 \mathrm{t} / \mathrm{h}$, oxygen stoichiometric ratio $\alpha$ is 0.4 . After fuel enters the reaction zone, particles are heated and ignited, the length of the oxygen zone substantially depends on the composition of the gasification agent $(0.6 \mathrm{~m}$ for air and $1.2 \mathrm{~m}$ for $\mathrm{O}_{2} / \mathrm{CO}_{2}$ mixture). This is due to the deterioration of the conditions for ignition of coal particles ([30, 31]). Under air gasification, fuel conversion takes place along the entire length of the reaction zone; under oxyfuel conditions, the core is much smaller.

All other conditions being equal (such as oxygen concentration, oxygen stoichiometric ratio, initial temperature), the gasification process under oxyfuel conditions occurs at lower temperatures, which is associated with the thermochemical properties of $\mathrm{CO}_{2}$ [5]: the specific heat capacity of $\mathrm{CO}_{2}$ is higher than that of $\mathrm{N}_{2}$; diffusivity of $\mathrm{O}_{2}$ and $\mathrm{H}_{2} \mathrm{O}$ in $\mathrm{CO}_{2}$ are lower than in $\mathrm{N}_{2} ; \mathrm{CO}_{2}$ enters endothermic reaction with the fuel carbon.

Cold gas efficiency $\eta_{\text {chem }}$ is commonly used as performance criterion of gasification process:

$$
\eta_{\text {chem }}=\frac{Q_{g} G_{g}}{Q_{f} G_{f}} 100 \%
$$

Here $Q_{f}$ is heating value of input fuel, $\mathrm{J} / \mathrm{kg} ; G_{f}$ is coal consumption, $\mathrm{kg} / \mathrm{h} ; Q_{g}$ is heating value of produced gas, $\mathrm{J} / \mathrm{Nm}^{3} ; G_{g}$ is gas production, $\mathrm{Nm}^{3} / \mathrm{h}$. Heating value of produced gas is determined by content of $\mathrm{CO}, \mathrm{H}_{2}$ and $\mathrm{CH}_{4}$. Gasification process characteristics are compared in Table 1. Under oxyfuel conditions, produced gas contains more $\mathrm{CO}$ and less $\mathrm{H}_{2}$, while heating value of is higher compared to air conditions. Despite temperature decrease, fuel conversion is also higher under oxyfuel conditions, which, apparently, is due to high concentration of gaseous oxidizer. Cold gas efficiency is also higher when using $\mathrm{O}_{2} / \mathrm{CO}_{2}$ mixtures.

Table 1. Comparison of gasification characteristics.

\begin{tabular}{|c|c|c|}
\hline Process outputs & $\mathrm{O}_{2} / \mathrm{N}_{2}$ & $\mathrm{O}_{2} / \mathrm{CO}_{2}$ \\
\hline $\mathrm{N}_{2}, \%$ & 57.75 & 1.04 \\
\hline $\mathrm{CO}_{2}, \%$ & 0.68 & 50.43 \\
\hline $\mathrm{H}_{2} \mathrm{O}, \%$ & 0.43 & 7.21 \\
\hline $\mathrm{CO}, \%$ & 29.88 & 34.69 \\
\hline $\mathrm{H}_{2}, \%$ & 10.12 & 5.37 \\
\hline $\mathrm{CH}_{4}, \%$ & 0.36 & 0.44 \\
\hline$Q_{g}, \mathrm{MJ} / \mathrm{Nm}^{3}$ & 5.02 & 5.52 \\
\hline$X_{C}, \%$ & 97.5 & 98.0 \\
\hline$\eta_{\text {chem }}, \%$ & 75.20 & 77.07 \\
\hline$T_{\text {max }}, \mathrm{K}$ & 1837 & 1322 \\
\hline$T_{\text {out }}, \mathrm{K}$ & 1320 & 1071 \\
\hline
\end{tabular}

Thus, the addition of $\mathrm{CO}_{2}$ can improve the efficiency of coal gasification, but significantly reduces the temperature of the process. Thermal stabilization of the gasification process is possible by increasing stoichiometric ratio [13], or by heating the gasification agent. Fuel gasification with high temperature air (HiTAG) was considered earlier in [21]. The possibility of a significant increase in efficiency by using a suitable blast composition (primarily, with the addition of water vapor) was shown. In contrast to this work, the characteristics of the gasification process in regimes with $\mathrm{CO}_{2}$ recirculation are considered here.
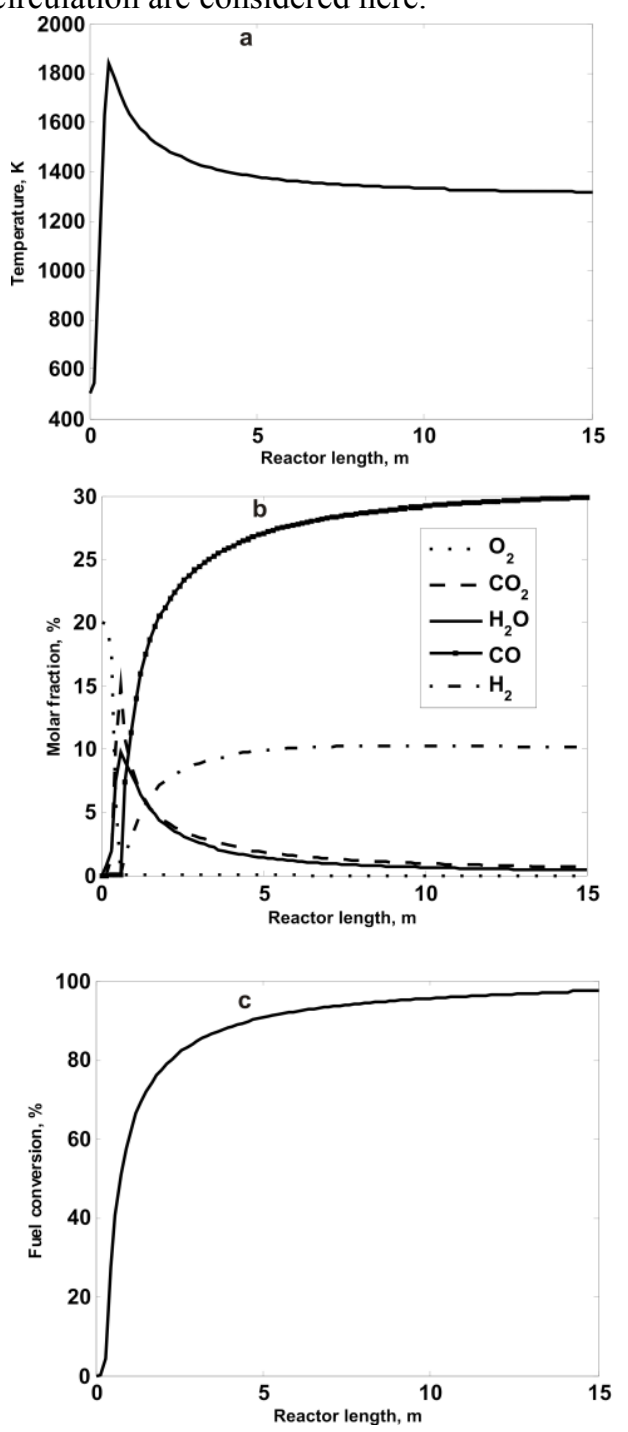

Fig. 1. Distribution of temperature, gas composition and fuel conversion degree along the reaction zone length under air gasification conditions.

Using the mathematical model, it is possible to optimize the gasification process by varying its parameters (first of all, the oxygen stoichiometric ratio). As is known from the thermodynamic analysis of gasification processes (see, for example, Ref. [32]), when gasifying solid fuels using oxygen-containing agent, there is an optimal stoichiometric ratio, which is determined by the conversion of fuel and oxidation of the produced gas. The value of the optimal oxidizer consumption depends on the process conditions: fuel and gasification agent composition, pressure, temperature, size of the reaction zone, etc. Figs. 3 and 4 shows the dependences of the cold gas efficiency of coal gasification process on the composition and oxygen 
stoichiometric ratio at oxygen concentration of $20 \%$ vol. Coal gasification in $\mathrm{O}_{2} / \mathrm{N}_{2}$ with a temperature of $573 \mathrm{~K}$ allows to achieve a cold gas efficiency of $72.8 \%$ at $\alpha=$ 0.4 ; the use of blast with the composition of $\mathrm{O}_{2} / \mathrm{CO}_{2}$ makes it possible to obtain an cold gas efficiency of $83.7 \%$ at $\alpha=0.3$. Such a sharp decrease in optimal stoichiometric ratio value is due to an increase in the concentration of the reacting gases. However, stationary modes of coal gasification in the $\mathrm{O}_{2} / \mathrm{CO}_{2}$ atmosphere are possible starting from $\alpha=0.25$. At $\alpha>0.45$, both dependences practically merge, since after complete carbon conversion, the process efficiency is determined by the oxidation of combustible components. An increase in the temperature of the gasification agent to $1173 \mathrm{~K}$ practically does not lead to a change in the cold gas efficiency of air gasification, however, the use of $\mathrm{O}_{2} / \mathrm{CO}_{2}$ mixture can increase the efficiency up to $95.4 \%$. But at the same time, the most efficient modes of oxyfuel gasification are close to the boundary of the thermal stability of the gasification process. Another possibility of thermal stabilization may be increasing the oxygen concentration in the $\mathrm{O}_{2} / \mathrm{CO}_{2}$ mixtures.
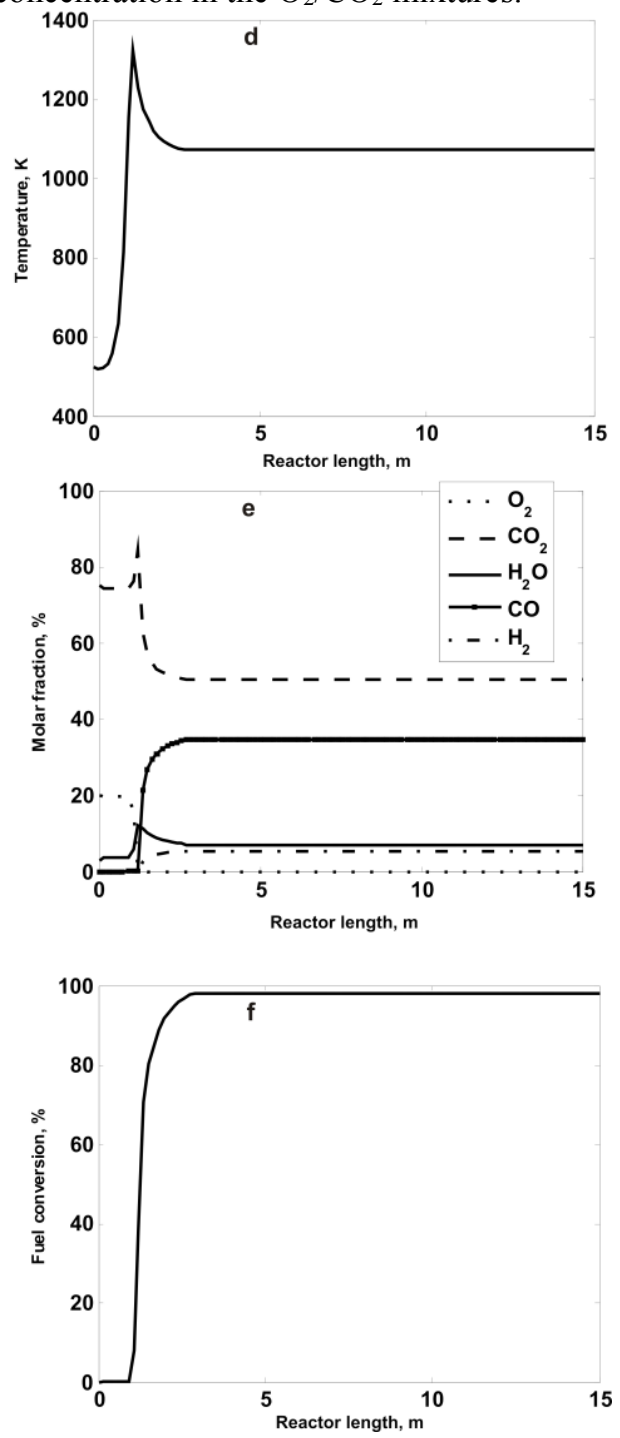

Fig. 2. Distribution of temperature, gas composition and fuel conversion degree along the reaction zone length under oxyfuel gasification conditions.
It should be noted that high-temperature heating of $\mathrm{O}_{2} / \mathrm{CO}_{2}$ mixtures under high pressure requires the use of special materials: these issues are not considered in this paper, since the main goal is to determine the limiting values of the oxyfuel technology characteristics.

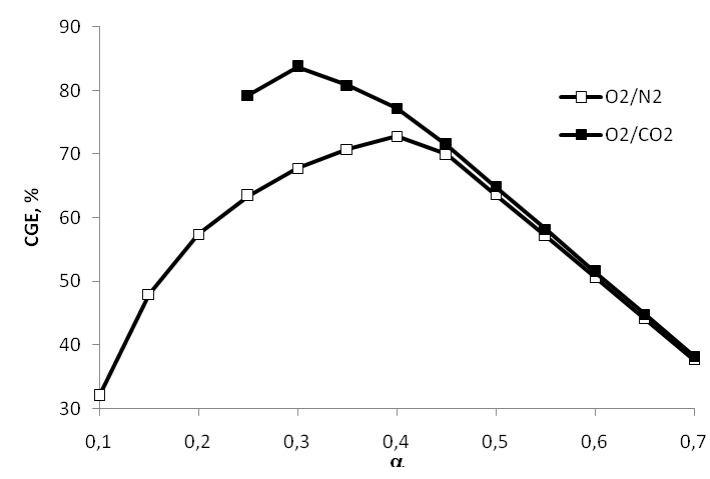

Fig. 3. Dependence of cold gas efficiency on stoichiometric ratio under initial gasification agent temperature $573 \mathrm{~K}$.

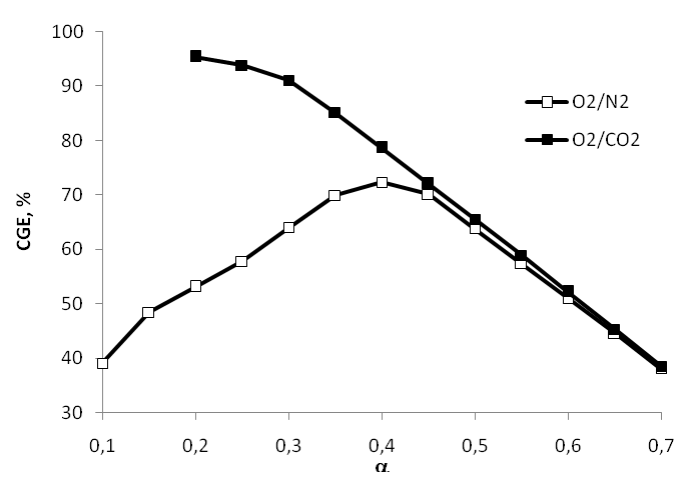

Fig. 4. Dependence of cold gas efficiency on stoichiometric ratio under initial gasification agent temperature $1173 \mathrm{~K}$.

\section{Conclusions}

Pulverized coal gasification process efficiency in $\mathrm{O}_{2} / \mathrm{N}_{2}$ (air conditions) and $\mathrm{O}_{2} / \mathrm{CO}_{2}$ (oxyfuel conditions) is estimated using mathematical modeling. It is shown that under equal stoichiometric ratio, the gasification temperature in $\mathrm{O}_{2} / \mathrm{CO}_{2}$ mixtures is $200-300 \mathrm{~K}$ lower nad cola gas efficiency is $10-20 \%$ higher compared to air conditions. Recycling of $\mathrm{CO}_{2}$ reduces the specific consumption of the oxidizing agent. Gasification agent heating makes it possible to increase the gasification process efficiency by the addition of $\mathrm{CO}_{2}$.

Oxyfuel gasification in this case is a promising way of high temperature heat recovery. The conversion of fuels using $\mathrm{CO}_{2}$ can be one of the ways to increase the efficiency of coal-fired thermal plants with the CCS. Of interest is the study of gasification processes with partial replacement of air nitrogen by $\mathrm{CO}_{2}$.

The work was supported by RF President grant for young candidates of sciences (MK-157.2020.8).

\section{References}


1. S. Suman, J. Clean. Prod. 181, 166 (2018). DOI: 10.1016/j.jclepro.2018.01.262

2. A.F. Ghoniem, Prog. Energy Comb. Sci. 37, 15 (2011). DOI: 10.1016/j.pecs.2010.02.006

3. D.Y.C. Leung, G. Caramanna, M.M. Maroto-Valer, Renew. Sust. Energy Rev., 39, 426 (2014). DOI: 10.1016/j.rser.2014.07.093

4. D. Tilman, J. Hill, C. Lehman, Science, 314, 1598 (2006). DOI: 10.1126/science.1133306

5. L. Chen, S.Z. Yong, A.F. Ghoniem, Prog. Energy Comb. Sci. 38, $156 \quad$ (2012). DOI: 10.1016/j.pecs.2011.09.003

6. V. Tola, A. Pettinau, Applied Energy 113, 1461 (2014). DOI: 10.1016/j.apenergy.2013.09.007

7. M.B. Toftegaard, J. Brix, P.A. Jensen, P. Glarborg, A.D. Jensen, Prog. Energy Comb. Sci. 36, 581 (2010). DOI: 10.1016/j.pecs.2010.02.001

8. C.-C. Cormos, Fuel 169, 50 (2016). DOI: 10.1016/j.fuel.2015.12.005

9. G. Cau, V. Tola, F. Ferrara, A. Porcu, A. Pettinau, Fuel 214, 423 (2018). DOI: 10.1016/j.fuel.2017.10.023

10. Z. Mao, L. Zhang, X. Zhu, C. Zheng, Fuel Proc. Tech. 162, 126 (2017). DOI: 10.1016/j.fuproc.2017.04.002

11. Y. Oki, S. Hara, S. Umemoto, K. Kidoguchi, H. Hamada, M. Kobayashi, Y. Nakao, Energy Procedia 63, $471 \quad$ (2014). 10.1016/j.egypro.2017.03.1192

12. P.A.Ralnikov, N.A. Abaimov, A.F. Ryzhkov, J. Phys.: Conf. Ser. 1128, 012007, (2018). DOI: 10.1088/1742-6596/1128/1/012007

13. H. Watanabe, S. Ahn, K. Tanno, Energy 118, 181 (2017). DOI: 10.1016/j.energy.2016.12.031

14. C. Liang, H. Zhang, Z. Zhu, Y. Na, Q. Lu, Fuel 200, 81 (2017). DOI: 10.1016/j.fuel.2017.03.032

15. K. Kidoguchi, S. Hara, Y. Oki, S. Kajitani, S. Umemoto, J. Inumaru, Proc. ASME 2011 Power Conf. 2, 485 (2011). DOI: 10.1115/POWER201155458

16. H. Tsuji, A.K. Gupta, T. Hasewaga, M. Katsuki, K. Kishimoto, M. Morita, High temperature air combustion. From energy conservation to pollution reduction (CRC Press, 2003). DOI: 10.1201/9781420041033

17. K. Yoshikawa, Proc. 2nd International Seminar on High Temperature Air Combustion (2000).

18. S. Sugiyama, N. Suzuki, Y. Kato, K. Yoshikawa, A. Omino, T. Ishii, K. Yoshikawa, T. Kiga, Energy 30, 399 (2005). DOI: 10.1016/j.energy.2004.06.001

19. A.F. Ryzhkov, N.A. Abaimov, I.G. Donskoy, D.A. Svishchev, Combust. Explos. Shock Waves 54, 337 (2018). DOI: 10.1134/S0010508218030103

20. I.G. Donskoy, Energy Systems Research 2, 55 (2019). DOI: 10.25729/esr.2019.03.0007
21. A.F.Ryzhkov, S.I. Gordeev, T.F. Bogatova, Thermal $\begin{array}{llll}\text { Eng. } & 62, & 796 & \text { (2015). }\end{array}$ 10.1134/S0040601515110075.

22. A.M. Kler, A.Yu. Marinchenko, Yu.M. Potanina, Bull. Tomsk Polytech. Univ. Geo Assets Eng. 329, 26 2019. DOI: 10.18799/24131830/2019/3/159

23. I.G. Donskoy, V.A. Shamansky, A.N. Kozlov, D.A. Svishchev, Combust. Theor. Model 21, 529 (2017). DOI: $10.1080 / 13647830.2016 .1259505$

24. I.G. Donskoi, Solid Fuel Chem. 50, 191 (2016). DOI: $10.3103 / \mathrm{S} 0361521916030034$

25. D.A. Frank-Kamenetskii, Diffusion and Heat Exchange in Chemical Kinetics (Princeton Univ. Press, 2015).

26. B.J. McBride, M.J. Zehe, S. Gordon, NASA Glenn Coefficients for Calculating Thermodynamic Properties of Individual Species (NASA|TP-2002211556) (Glenn Research Center, Cleveland, 2002)

27. J.O. Hirschfelder, C.F. Curtiss, R.B. Bird, M.G. Mayer, Molecular theory of gases and liquids (Wiley, New York, 1954).

28. A.V. Messerle, V.E. Messerle, A.B. Ustimenko, High Temp. 55, 352 (2017). DOI: 10.1134/S0018151X17030142

29. B.M. Kaganovich, S.P. Filippov, A.V. Keiko, V.A. Shamanskii, Thermal Eng. 58, 143 (2011). DOI: 10.1134/S0040601511020054

30. T. Maffei, R. Khatami, S. Perucci, T. Faravelli, E. Ranzi, Y.A. Levendis, Comb. Flame 160, 2559 (2013). DOI: 10.1016/j.combustflame.2013.06.002

31. H. Watanabe, K. Tanno, H. Umetsu, S. Umemoto, Fuel 142, $250 \quad$ (2015). 10.1016/j.fuel.2014.11.012

32. M.J.Prins, K.J. Ptasinski, F.J.J.G. Janssen, Energy 32, $1248 \quad$ (2007). 10.1016/j.energy.2006.07.017 